\title{
Effect of selenium supplementation on HIV-1 RNA detection in breast milk of Tanzanian women
}

\section{Citation}

Sudfeld, Christopher R., Said Aboud, Roland Kupka, Ferdinand M. Mugusi, and Wafaie W. Fawzi. 2014. "Effect of Selenium Supplementation on HIV-1 RNA Detection in Breast Milk of Tanzanian Women." Nutrition 30 (9) (September): 1081-1084. doi:10.1016/j.nut.2014.01.011.

\section{Published Version}

doi:10.1016/j.nut.2014.01.011

\section{Permanent link}

http://nrs.harvard.edu/urn-3:HUL.InstRepos:26863669

\section{Terms of Use}

This article was downloaded from Harvard University's DASH repository, and is made available under the terms and conditions applicable to Open Access Policy Articles, as set forth at http:// nrs.harvard.edu/urn-3:HUL.InstRepos:dash.current.terms-of-use\#OAP

\section{Share Your Story}

The Harvard community has made this article openly available.

Please share how this access benefits you. Submit a story.

Accessibility 


\title{
Effect of Selenium Supplementation on HIV-1 RNA Detection in Breast Milk of Tanzanian Women
}

\author{
Christopher R. Sudfeld, ScD ${ }^{1,{ }^{*}}$, Said Aboud, MD ${ }^{4}$, Roland Kupka, ScD ${ }^{2,6}$, Ferdinand M. \\ Mugusi, MD ${ }^{5}$, and Wafaie W. Fawzi, MBBS, $\operatorname{DrPH}^{1,2,3}$ \\ ${ }^{1}$ Department of Global Health, Harvard School of Public Health, Boston, MA, USA. \\ 2Department of Nutrition, Harvard School of Public Health, Boston, MA, USA. \\ ${ }^{3}$ Department of Epidemiology, Harvard School of Public Health, Boston, MA, USA. \\ ${ }^{4}$ Department of Microbiology and Immunology, Muhimbili University of Health and Allied \\ Sciences, Dar es Salaam, Tanzania. \\ ${ }^{5}$ Department of Internal Medicine, Muhimbili University of Health and Allied Sciences, Dar es \\ Salaam, Tanzania. \\ ${ }^{6}$ UNICEF West and Central Africa Regional Office, Dakar, Senegal.
}

\section{Abstract}

Objective-Selenium supplementation for HIV-infected women may increase genital shedding of HIV-1, but no studies have examined the effect on viral shedding in breast milk.

Research Methods and Procedures-HIV-infected pregnant women enrolled at 12-27 weeks gestation in a randomized, double-blind, placebo-controlled trial of daily selenium ( $200 \mu \mathrm{g}$ as selenomethionine) had cell-free HIV-1 RNA quantified in breast milk at 4-9 weeks postpartum. All participants received high dose multivitamins containing vitamin B-complex, $\mathrm{C}$, and $\mathrm{E}$ as standard of care.

\begin{abstract}
Results-The proportion of women with detectable ( $>50$ copies $/ \mathrm{mL}$ ) HIV-1 RNA in breast milk appeared to be increased in the selenium group (36.4\%) as compared to the placebo (27.5\%) among the total cohort $(\mathrm{n}=420)$, but results were borderline statistically significant (RR: 1.32; $95 \%$ CI: $1.00-1.76 ; \mathrm{p}=0.05)$. In secondary analyses, the proportion of women with detectable HIV-1 RNA in breast milk was significantly greater in the selenium group (37.8\%) as compared to
\end{abstract}

\footnotetext{
(c) 2014 Elsevier Inc. All rights reserved.

"Correspondence: Christopher R. Sudfeld, Harvard School of Public Health, 1639 Tremont Street, Boston, MA 02120, Telephone: (617)432-5299, csudfeld@mail.harvard.edu, Fax: (617) 432-1355.

Publisher's Disclaimer: This is a PDF file of an unedited manuscript that has been accepted for publication. As a service to our customers we are providing this early version of the manuscript. The manuscript will undergo copyediting, typesetting, and review of the resulting proof before it is published in its final citable form. Please note that during the production process errors may be discovered which could affect the content, and all legal disclaimers that apply to the journal pertain.

Authorship: SA, RK, FMM, and WWF designed and conducted the trial. SA lead quantification of breast milk viral load. CS analyzed the data and drafted the manuscript. All authors reviewed and approved the final manuscript.

Conflicts of Interest: No conflicts of interest were declared.

Disclaimer: Roland Kupka is a UNICEF staff member. The opinions and statements in this article are those of the author and may not reflect official UNICEF policies.
} 
placebo (27.5\%) among women who did not receive HAART (RR: 1.37; 95\% CI: 1.03-1.82; $\mathrm{p}=0.03$ ). This relationship was primarily due to a significant effect of selenium among primiparous women (RR: 2.24; 95\% CI: 1.30-3.86; p<0.01), but not multiparous women (RR: 1.14; 95\% CI: $0.81-1.59 ; \mathrm{p}=0.54$ ) ( $\mathrm{p}$-value for interaction=0.02). Too few women received HAART in this study $(n=12)$ to establish the effect of selenium supplementation.

Conclusions-Selenium supplementation appears to increase HIV-1 RNA detection in breast milk among primiparous women not receiving HAART. Safety studies among pregnant women on HAART need to be conducted before providing selenium containing supplements.

\section{Keywords}

HIV; Selenium; Milk; Micronutrients; Randomized Controlled Trial

\section{Introduction}

Micronutrient deficiencies are common in HIV-infected individuals, particularly among pregnant and lactating women due to additional nutritional demands [1]. Selenium is an essential micronutrient which plays a role in antioxidant defense and also supports immune system functioning [2,3]. Randomized controlled trials determined selenium supplementation may provide modest benefits for HIV-infected adults including decreased diarrhea incidence and hospitalizations and possibly improved survival of children born to HIV-infected pregnant women [1-5]. Nevertheless, selenium supplementation may also have some adverse effects. An observational study suggests selenium may increase genital tract shedding of HIV-1 RNA in pregnant women, which may lead to increased mother to child transmission (MTCT) of HIV [6]. No studies have examined the effect of selenium supplements on breast milk shedding of HIV-1 to determine if selenium provision may increase risk MTCT during the breastfeeding period.

In this study we examined the effect of selenium supplementation on HIV-1 RNA detection in breast milk at 4-9 weeks postpartum among HIV-infected women enrolled in a randomized clinical trial conducted in Dar es Salaam, Tanzania [3]. We secondarily investigate potential effect modification by markers of HIV disease severity, receipt of highly active antiretroviral therapy (HAART), and parity.

\section{Materials and Methods}

\section{Study design and population}

HIV-infected pregnant women between 12 and 27 weeks of gestation were enrolled in a randomized, parallel group, double-blind, placebo-controlled trial of selenium supplementation conducted in Tanzania during September 2003 to August 2006 (clinicaltrials.gov identifier: NCT00197561) [3]. The study statistician based in Boston, MA prepared a computer-generated randomization list in blocks of 20. Study pharmacists stored the coded randomization list in a locked file cabinet and concealed allocation by covering the numeric regimen code on each bottle. After obtaining informed consent, women were randomly assigned to receive a daily tablet of $200 \mu \mathrm{g}$ elemental selenium (selenomethionine) or placebo from enrollment to trial discharge at 6 months postpartum. The selenium dose is 
one-half of the tolerable upper intake level of $400 \mu \mathrm{g} / \mathrm{d}$ for pregnant women [7]. At monthly clinic visits, a new bottle containing 45 tablets of the trial regimen was given to each woman, and research nurses counted tablets remaining in the bottle from the previous month.

All participants had access to free prenatal including daily doses of ferrous sulphate (200 $\mathrm{mg}$, equivalent to $60 \mathrm{mg}$ ferrous iron), folic acid $(0.25 \mathrm{mg})$, and sulfadoxine-pyrimethamine tablets for malaria prophylaxis (Fansidar, Roche Pharmaceuticals, Nutley, NJ). Based on previous findings, all women also received multivitamins containing vitamins B-complex, $\mathrm{C}$ and $\mathrm{E}$ at multiples of the recommended dietary allowances (RDAs) as standard of care from enrollment until delivery (20 mg thiamine, $20 \mathrm{mg}$ riboflavin, $25 \mathrm{mg}$ vitamin B-6, $100 \mathrm{mg}$ niacin, $50 \mu \mathrm{g}$ vitamin B-12, $500 \mathrm{mg}$ vitamin C, $30 \mathrm{mg}$ vitamin E, and $0.8 \mathrm{mg}$ folic acid) [8]. To prevent mother to child HIV transmission, a single dose of nevirapine $(200 \mathrm{mg})$ was given orally to all women during labor and a dose of nevirapine $(2 \mathrm{mg} / \mathrm{kg})$ was given to infants within 72 hours of delivery. Access to antiretrovirals became available during the study period and 31 enrolled women were initiated on HAART during follow-up. Women were eligible for HAART if they had WHO stage IV HIV disease, a CD4 cell count of $<200$ cells $/ \mu \mathrm{L}$, or WHO stage III and a CD4 T-cell count of $<350$ cells $/ \mu \mathrm{L}$. The trial protocol was approved by the institutional review boards at the Harvard School of Public Health and Muhimbili University of Health Sciences and Allied Sciences.

\section{Data Collection}

At the baseline study visit, research nurses collected data on education, pregnancy history, anthropometry, breastfeeding, and current health status for enrolled women. Blood samples were also obtained and absolute CD4 T-cell counts (FACSCount system, Becton Dickinson, San Jose, CA), hemoglobin concentrations (AcT Diff II analyzer, Beckman Coulter, Miami, FL), and plasma viral loads (Amplicor HIV-1 Monitor Test version 1.5, Roche Diagnostics, Indianapolis, IN) were determined.

Participants were followed at monthly clinic visits until 6 months postpartum. Mothers were asked to provide a breast milk sample at the first or second monthly clinic visit postpartum (4-9 weeks) to allow for missed clinic visits and low breast milk output at the time of collection. A breast milk aliquot was centrifuged at $1500 \times \mathrm{g}$ for $12 \mathrm{~min}$ at $4^{\circ} \mathrm{C}$ and the cellfree aqueous milk fraction and milk pellet were separately stored at $-70^{\circ} \mathrm{C}$. HIV-1 viral load in the cell-free aqueous milk fraction was quantified using the ultrasensitive protocol of the Amplicor HIV-1 Monitor Test (version 1.5; Roche Diagnostics). The lower limit of detection was 50 viral copies/mL.

\section{Statistical Analysis}

Statistical analyses were based on the intention-to-treat principle. Detectable HIV-1 RNA in breast milk ( $>50$ viral copies $/ \mathrm{mL}$ ) was considered as the primary dichotomous endpoint. Breast milk viral load was not analyzed continuously due to the majority of samples being below the detection limit of the assay. The chi-square test was used to compare the proportion of participants with detectable HIV-1 RNA in breast milk by treatment regimen. 
Risk ratios and corresponding 95\% confidence intervals were also obtained by modeling using the log link and the binomial variance function.

To examine the potential effect modifiers based on a search of the literature and biologic plausibility, we performed stratified analyses by baseline age ( $<30$ years vs. $\geq 30$ years), prior pregnancies $(0$ vs. $\geq 1)$, CD4 T-cell count $(<350$ vs. $\$ 350$ cells $/ \mu \mathrm{L})$, breastfeeding at time of breast milk sample collection, receipt of HAART, and plasma viral load $(<4.0 \mathrm{vs.}$ $\geq 4.0 \log$ copies $/ \mathrm{mL}$ ). To assess the statistical significance of each interaction, we used the Wald test for risk-ratio homogeneity. Statistical analyses were carried out with SAS system version 9.1 (SAS Institute Inc).

\section{Results}

In the parent trial a total of 915 pregnant women between 12 and 27 weeks of gestation were randomized during September 2003 to August 2006, of which 832 (90.2\%) were alive, had a living child, and were enrolled in the study at 4 weeks postpartum. Breast milk samples at 4-9 weeks postpartum for detection of HIV-1 RNA were available for 420 women (50.4\%). A total of $127(15.2 \%)$ women terminated breastfeeding before 4 weeks postpartum and of these women only 14 were able to provide breast milk samples. The only significant difference was women who provided an adequate sample for measurement breast milk viral loads were older (median: 28.0 years) as compared to enrolled women without a breast milk viral load measurement (median 27.0 years) $(\mathrm{p}=0.02)$.

Baseline characteristics of women with breast milk HIV-1 RNA measurements are presented in Table 1 stratified by randomized treatment group. There were no significant baseline differences between treatment groups. Randomized regimen compliance, determined as the percent of daily regimen tablets not returned at the following monthly clinic visit, was similarly high in the selenium (mean $\% \pm$ SD: $91.2 \pm 5.8$ ) and placebo group $(91.7 \pm 5.7)$ $(\mathrm{p}=0.46)$.

Table 2 presents the effect of selenium supplementation on detectable HIV-1 RNA in breast milk ( $>50$ copies $/ \mathrm{mL}$ ) at $4-9$ weeks postpartum, stratified by effect modifiers. The proportion of women with detectable HIV-1 RNA in breast milk ( $>50$ copies $/ \mathrm{mL}$ ) among the total study population appeared to be increased for women in the selenium group (76 of 209, $36.4 \%$ ) as compared women in the placebo group (58 of $211,27.5 \%$ ), but results were borderline statistically significant (RR: 1.32 ; $95 \%$ CI: $1.00-1.76$; $\mathrm{p}=0.05$ ).

We then performed exploratory analyses to investigate potential effect modifiers of the relationship. The effect of selenium on HIV-1 detection in breast milk appeared to differ by receipt of HAART (p-value for interaction: 0.07). Among women who did not receive HAART, the proportion of women with detectable HIV-1 RNA in breast milk was significantly greater for women in the selenium group ( 76 of $201,37.8 \%$ ) as compared to placebo (57 of 207, 27.5\%) (RR: 1.37; 95\% CI: 1.03-1.82; $\mathrm{p}=0.03$ ).

Subsequently, we examined additional effect modifiers among women who did not receive HAART and determined the relationship of selenium supplementation with HIV-1 RNA detection significantly varied by parity ( $\mathrm{p}$-value for interaction=0.02). Among primiparous 
women who did not receive HAART, the proportion of women with detectable HIV-1 RNA was significantly greater for the selenium group ( 26 of $49,53.1 \%)$ as compared to the placebo group (13 of 55, 23.6\%) (RR: 2.24; 95\% CI: 1.30-3.86; p<0.01). Among multiparous women who did not receive HAART, the proportion of women with detectable HIV-1 RNA did not differ for women randomized to selenium (50 of 152, 32.9\%) versus placebo (58 of 211, 29.0\%) (RR: 1.14; 95\% CI: 0.81-1.59; $\mathrm{p}=0.54$ ).

\section{Discussion}

We found the effect of selenium supplementation on breast milk shedding of HIV-1 varied by receipt of HAART and parity. Among primiparous women who did not receive HAART, women randomized to the selenium group has significantly increased risk of HIV-1 RNA detection as compared to the placebo group. There was no significant effect of selenium supplements on breast milk HIV-1 RNA detection for multiparous women who did not receive HAART.

Previous observational studies and randomized controlled trials have suggested selenium supplementation may increase genital HIV-1 shedding. In an observational cohort study conducted among pregnant women in Tanzania, individuals with plasma selenium concentrations $\geq 114 \mu \mathrm{g} / \mathrm{L}$ had increased risk of lower-genital tract shedding of HIV-1 RNA [6]. A randomized trial of multivitamins supplements containing vitamin B-complex, C, E +

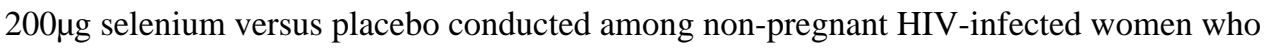
did not receive HAART also suggested a negative effect of supplements containing selenium on genital tract shedding [9]. Women randomized to the multivitamin group had 2.5 times (95\% CI: 1.3-3.7) the risk of vaginal HIV-1 infected cell shedding and increased quantity of HIV-RNA in vaginal secretions in the multivitamin group, after adjusting for potential baseline imbalances. These results are in contrast to a randomized trial of multivitamin supplements containing vitamin B-complex, C, E versus placebo conducted among Tanzanian pregnant women who did not receive HAART, which found no difference in HIV-1 RNA detection in cervicovaginal lavage samples between groups [10]. The daily dose of vitamin B-complex, C, E was identical for these two trials and therefore the inconsistent results for genital shedding may potentially be attributed to the additional selenium component of the multivitamin in the Kenyan trial.

In this study we found significant effect modification of the relationship between selenium supplementation and breast milk viral load detection by parity, but these results should be considered exploratory. A potential explanation is primiparous women may have increased concentration of selenium in breast milk as compared to multiparous women leading to a dose-response relationship. A study of rural Gambian women determined increased parity was negatively correlated with breast milk selenium concentration, after taking in account season as a surrogate for food scarcity [11]. An alternative explanation to the observed interaction of selenium supplements and parity may be due to analysis of a binomial HIV-1 RNA detection outcome as compared to continuous HIV-1 viral load. For example, primiparous women may have on average higher breast milk viral loads within the undetectable range ( $<50$ copies $/ \mathrm{mL}$ ) as compared to multiparous women. For the same absolute increase in HIV-1 viral load in breast milk due to selenium supplementation, a 
larger proportion of primiarious women may reach the detectable threshold as compared to multiparous women. As a result, additional studies are needed to determine if our findings represent biologic interaction or are a result of the analysis.

A limitation of this study is few women in this study received HAART, which is known to significantly decrease cell-free HIV-1 RNA levels and risk of MTCT, and therefore our results may not be directly generalizable to these women [12,13]. Second, sodium to potassium (Na:K) breast milk concentration ratio, as an assessment of subclinical mastitis, was not available in our study and may have helped explain biologic mechanisms. We also did not have detailed information on breast health or breastfeeding practices.

\section{Conclusion}

Selenium supplementation may have a modest beneficial effect on diarrhea and birth outcomes for HAART naïve pregnant women, but increased risk of breast milk and genital HIV shedding do not support providing selenium supplements to these women. Studies examining the balance of potential benefits and risks for women receiving HAART will be needed before providing selenium containing supplements.

\section{Acknowledgments}

We thank the mothers and children and the members of the research team, including physicians, nurses, midwives, supervisors, laboratory staff, and administrative staff, who made the study possible. We also thank the Permanent Secretary, Ministry of Health, and the officials at Muhimbili University of Health and Allied Sciences, Muhimbili National Hospital, the City of Dar es Salaam Regional Health Authority, and the National AIDS Control Program for their support.

Source of Funding: This trial was supported by the National Institute of Child Health and Human Development (NICHD R24 043555-05).

\section{References}

1. Siegfried N, Irlam JH, Visser ME, et al. Micronutrient supplementation in pregnant women with HIV infection. Cochrane Database Syst Rev. 2012; 3:CD009755. [PubMed: 22419344]

2. Stone CA, Kawai K, Kupka R, et al. Role of selenium in HIV infection. Nutr Rev. 2010; 68:671681. [PubMed: 20961297]

3. Kupka R, Mugusi F, Aboud S, et al. Randomized, double-blind, placebo-controlled trial of selenium supplements among HIV-infected pregnant women in Tanzania: effects on maternal and child outcomes. Am J Clin Nutr. 2008; 87:1802-1808. [PubMed: 18541571]

4. Kupka R, Mugusi F, Aboud S, et al. Effect of Selenium Supplements on Hemoglobin and Morbidity among HIV-infected Tanzanian Women. Clin Inf Dis. 2009; 48:1475-1478.

5. Burbano X, Miguez-Burbano MJ, McCollister K, et al. Impact of a selenium chemoprevention clinical trial on hospital admissions of HIV-infected participants. HIV Clin Trials. 2002; 3:483-491. [PubMed: 12501132]

6. Kupka R, Msamanga GI, Xu C, et al. Relationship between plasma selenium levels and lower genital tract levels of HIV-1 RNA and interleukin 1-B. Eur J of Clin Nutr. 2007; 61:542-547. [PubMed: 17151590]

7. Food and Nutrition Board. DRI: dietary reference intakes for vitamin C, vitamin E, selenium, and carotenoids. Washington, DC: National Academy Press; 2000.

8. Fawzi WW, Msamanga GI, Spiegelman D, et al. Randomised trial of effects of vitamin supplements on pregnancy outcomes and T cell counts in HIV-1-infected women in Tanzania. Lancet. 1998; 351:1477-1482. [PubMed: 9605804] 
9. McClelland RS, Baeten JM, Overbaugh J, et al. Micronutrient supplementation increases genital tract shedding of HIV-1 in women: results of a randomized trial. J Acquir Immune Defic Syndr. 2004; 37:1657-1663. [PubMed: 15577425]

10. Fawzi W, Msamanga G, Antelman G, et al. Effect of prenatal vitamin supplementation on lowergenital levels of HIV type 1 and interleukin type 1 beta at 36 weeks of gestation. Clin Infect Dis. 2004; 38:716-722. [PubMed: 14986257]

11. Funk MA, Hamlin L, Picciano MF, et al. Milk selenium of rural African women: influence of maternal nutrition, parity, and length of lactation. Am J Clin Nutr. 1990; 51:220-224. [PubMed: 2305708]

12. Slyker JA, Chung MH, Lehman DA, et al. Incidence and correlates of HIV-1 RNA detection in the breast milk of women receiving HAART for the prevention of HIV-1 transmission. PLoS One. 2012; 7:e29777. [PubMed: 22253778]

13. Rousseau CM, Nduati RW, Richardson BA, et al. Association of levels of HIV-1-infected breast milk cells and risk of mother-to-child transmission. J Infect Dis. 2004; 190:1880-1888. [PubMed: 15499546] 


\section{Table 1}

Baseline characteristics by treatment group

\begin{tabular}{|c|c|c|c|c|}
\hline \multirow[b]{2}{*}{ Baseline Characteristics } & \multicolumn{2}{|c|}{ Selenium Group } & \multicolumn{2}{|c|}{ Placebo Group } \\
\hline & $\mathbf{n}$ & $\begin{array}{c}\text { Mean } \pm \text { SD } \\
\text { or Frequency } \\
(\%)\end{array}$ & $\mathbf{n}$ & $\begin{array}{c}\text { Mean } \pm \text { SD } \\
\text { or Frequency } \\
(\%)\end{array}$ \\
\hline Age (years) & 209 & $28.2 \pm 4.9$ & 211 & $27.9 \pm 5.0$ \\
\hline Level of education (years) & 207 & & 208 & \\
\hline None or adult education & & $19(9.2)$ & & $22(10.6)$ \\
\hline $1-4$ & & $7(3.4)$ & & $11(5.3)$ \\
\hline $5-8$ & & $130(62.8)$ & & $139(65.9)$ \\
\hline$>8$ & & $51(24.6)$ & & $36(17.3)$ \\
\hline Gestational age (weeks) & 209 & $21.4 \pm 3.4$ & 211 & $21.4 \pm 3.5$ \\
\hline Prior pregnancies & 207 & & 208 & \\
\hline 0 & & $50(24.2)$ & & $55(26.4)$ \\
\hline $1-3$ & & $145(70.0)$ & & $137(65.9)$ \\
\hline$>3$ & & $12(5.8)$ & & $16(7.7)$ \\
\hline CD4 T-cell count (cells/ $\mu \mathrm{L})$ & 146 & & 148 & \\
\hline$<200$ & & $35(24.0)$ & & $24(16.2)$ \\
\hline $200-350$ & & $44(30.1)$ & & $45(30.4)$ \\
\hline$>350$ & & $67(45.9)$ & & $79(53.4)$ \\
\hline Duration Breastfeeding (weeks) & 205 & $16.5 \pm 6.7$ & 204 & $15.8 \pm 6.9$ \\
\hline MUAC (cm) & 200 & $26.3 \pm 3.1$ & 204 & $25.9 \pm 2.9$ \\
\hline Hemoglobin (g/L) & 149 & $98 \pm 13$ & 152 & $97 \pm 13$ \\
\hline Plasma viral load (log) & 105 & $4.0 \pm 0.9$ & 104 & $4.0 \pm 0.9$ \\
\hline
\end{tabular}


